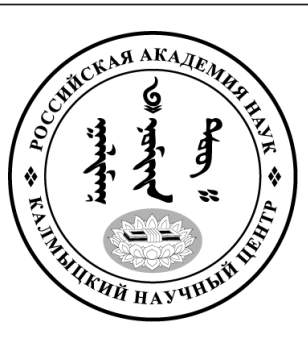

Published in the Russian Federation

Oriental Studies (Previous Name: Bulletin of the Kalmyk Institute for Humanities of the Russian Academy of Sciences)

Has been issued as a journal since 2008

ISSN: 2619-0990; E-ISSN: 2619-1008

Is. 3, pp. 423-440, 2019

DOI: $10.22162 / 2619-0990-2019-43-3-423-440$

Journal homepage: https://kigiran.elpub.ru

УДК 294.321

\title{
Тибетский спор о «двух истинах» и квантово-механическая концепция Эверетта-Менского
}

\author{
Андрей Анатольевич Терентьев ${ }^{I}$ \\ ${ }^{1}$ независимый исследователь (д. 45, Таврическая ул., 191015 Санкт Петербург, Российская \\ Федерация) \\ кандидат исторических наук \\ ORCID: 0000-0002-2792-5519. E-mail: narthang@gmail.com
}

\begin{abstract}
Аннотация. Введение. Буддийское учение о «двух истинах», то есть двух слоях реальности обыденном и «высшем» - оказалось чрезвычайно похожим на современное квантово-механическое представление о мире в интерпретации Эверетта, расширенной российским физиком М. Б. Менским. Онтологическое понимание доктрины о «двух истинах», представленное в тибетской мадхьямаке Чже Цонкапой, было подвергнуто острой критике Горампой Сонамом Сенге из школы сакья. Цель. В статье, после изложения основных положений доктрины «двух истин» и концепции Эверетта-Менского, рассматриваются спорные проблемы в интерпретации «двух истин» Цонкапой и Горампой, и в заключение делается попытка оценить позиции этих философов с точки зрения указанной интерпретации квантовой механики.

Ключевые слова: две истины, тибетская мадхьямака, квантовая механика, Цонкапа, Горампа, Эверетт, Менский.

Для цитирования: Терентьев А. А. Тибетский спор о «двух истинах» и квантово-механическая концепция Эверетта-Менского. Oriental Studies. 2019;(3): 423-440. DOI: 10. 22162/26190990-2019-43-3-423-440.
\end{abstract}

UDC 294.321

\section{The Tibetan 'Two Truths' Debate and Everett-Mensky's Interpretation of Quantum Mechanics}

\author{
Andrey A. Terentyev ${ }^{l}$ \\ ${ }^{1}$ Independent Researcher (45, Tavricheskaya Str., St. Petersburg 191015, Russian Federation) \\ Ph.D. (History) \\ ORCID: 0000-0002-2792-5519. E-mail: narthang@gmail.com
}

\begin{abstract}
Introduction. The Buddhist teaching on 'two truths', i.e. the 'two levels of reality' empirical and ultimate ones - proved to be very close to the modern quantum mechanical worldview as presented by H. Everett and developed by the Russian physicist M. B. Mensky. The ontological contents of the Two Truths Doctrine posited in Tibetan Madhyamaka by Je Tsongkhapa was debated by Gorampa Sonam Senge from Sakya. Goals. Having presented the main ideas of the 'two truth'
\end{abstract}


doctrine and the Everett-Mensky concept, the paper considers the main problems of the interpretation of the 'two truths' by Tsongkhapa and Gorampa, and finally turns to the above quantum-mechanical theory to evaluate the positions of these philosophers.

Keywords: two truths, Tibetan Madhyamaka, quantum mechanics, Tsongkhapa, Gorampa, Everett, Mensky

For citation: Terentyev A. The Tibetan 'Two Truths' Debate and Everett-Mensky's Interpretation of Quantum Mechanics. Oriental Studies. 2019;(3): 423-440. DOI: 10.22162/2619-0990-2019-43-3423-440.

\section{Введение}

\section{Буддийское представление о «двух} истинаху

Наиболее общие онтологические категории буддизма - это сансара (мир явлений) и нирвана (мир «покоя»). При этом Будда рассматривал мир явлений как мир человека и человеческого опыта: этот мир, сансаpa, описывается в имеющих субъективное измерение категориях пяти скандх, 12 аятан или 18 дхату․․ Сансара при постижении её $n y c m o m b l$, т. е. взаимообусловленности всех явлений, и оказывается нирваной.

Эти два слоя бытия - нирвану и сансару - также можно обозначить как мир абсолютной реальности и мир относительной реальности. И связываются они через понятие nycmombl, как переводят обычно на русский язык санскритский термин «шуньята» ${ }^{2}$. Разделение этих двух уровней реальности - сущностного, «абсолютного» (пали: paramattha; санскр.: paramārtha) и явленного, условного, «относительного» (пали: samuti; санскр.: saṃvrti) $)^{3}$ принято называть

1 Скандхи («совокупности»), аятаны («базы») и дхату («группы элементов») - три параллельные сетки категорий, описывающих в буддизме воспринимаемый мир.

2 Отметим, что это не совсем удачный перевод, из-за которого эту важную буддийскую философскую категорию часто путают с физическими понятиями, такими как вакуум или пространство. Ф. И. Щербатской, например, предлагал переводить шуньяту как «относительность», используя терминологию тех физических теорий, которые возникли в его время [Stcherbatsky 1936], но шуньята - это прежде всего взаимозависимость, отсутствие независимости, самобытия любой вещи или мысли.

3 Интересно, как отмечает Карунадаca [Karunadasa 2014: 64], что разница между sammuti и saṃṿ̣ti выходит за рамки различий между санскритом и пали: «саммути имеет дру- теорией «двух истин» ${ }^{4}$. Обычному воспри-

гую этимологию и значение - оно происходит от корня man (думать) и с приставкой sam o3начает согласие, условную договорённость или общепринятую договорённость. Самврити, с другой стороны, происходит от корня vṛ (покрывать, закрывать) и с приставкой sam означает покрытие, сокрытие» [Karunadasa 2014: 64] (3десь и далее перевод автора статьи).

4 Этот перевод еще больше, чем «пустота», дезориентирует читателя. В традиционной европейской мысли (если отвлечься от специальных разработок этого понятия) «истиной» мы называем прежде всего соответствие понятия его объекту, здесь же речь идет о совершенно другом: о двух уровнях бытия. Но санскритское слово satya (которое и переводится обычно как «истина») производно от корня sat, «быть, существовать». То есть «сатья» - это буквально «то, что есть» - что далеко не во всех контекстах можно перевести как «истина». Однако в русском языке, как подсказывал ещё В. Даль, истина есть «естина»: «И́стина — ... всё, что верно, подлинно, точно, справедливо, что есть всё что есть, то истина, не одно ль и то же есть и естина, истина?» [Даль 1881: 59]. Как отмечал Д. С. Рюэгг, «... переводы слова сатья как „истина“" или ,реальность“ нацелены на соответствие, хотя и грубое, двум аспектам самврити-сатьи субъективному аспекту познавания (jñāna=shes pa, blo, yul can) или выражения (abhidhāna=rjod byed) - и объективному объекту (vișaya=yul), то есть познаваемому (jñeya=shes bya) или выраженному (abhidheya=brjod bya)» [Ruegg 2002: 198].

Возможно, в некоторых случаях, более удачным переводом пары категорий самврити-сатья и парамартха-сатья (тиб.: kun dzob bden pa, don dam pa'i bden pa), обозначающих относительный мир явлений и скрывающийся за ним реальный, «истинный» мир, было бы использование парных европейских категорий «явление и сущность»: «Истина бытия - это сущность», определял Гегель [Гегель 1971: 7]. В индийской 
ятию или мышлению доступен только относительный мир, самврити, только в нем реальность делится на объект и субъект, а также имеется дискурсивное мышление. Парамартха же - подлинная реальность, сущность - постигается лишь теми, кто достиг непосредственного восприятия $n y$ cmombl, то есть «святыми», арья (санскр. ārya).

Пониманию и интерпретациям этой доктрины буддийские мыслители и буддологи посвятили тысячи страниц ${ }^{5}$. Для начала, однако, отметим лишь сам принцип нахождения в действительности двух слоев: обыденного, который мы все, как кажется, знаем в той или иной степени, и скрывающегося за ним сущностного слоя подлинной реальности, назовем ли мы ее нирваной, дхармадхату, татхатой или иными словами (суть ее, как и кантовской «вещи в себе», все равно выразить словами невозможно) - важно, что она доступна восприятию лишь тех, кто непосредственно видит пустоту, взаимообусловленность всех явлений.

«Учение Будды основано на двух естинах

(satya):

обыденной естине (samvrti), и естине в высшем смысле (paramārtha) ${ }^{6}$.

философии, насколько мне известно, соответствующей пары категорий — «сущность и явление» - нет.

5 В частности, теорию двух истин в палийской Абхидхамме описывает Карунадаса [Karunadasa 2014: 63]: «Хотя это разделение [на две истины. - A. T.] и является абхидхаммической инновацией, ... идеи, приведшие к его формулировке, могут быть прослежены и в ранних буддийских текстах. Примером этого в Ангуттара-никае является разделение на nitattha и neyyattha - речения прямого смысла и подразумеваемого <...> Этому придавалось такое большое значение, что не заметить его означало исказить учение Будды: „Кто представит сутру прямого смысла как сутру подразумеваемого смысла, или [наоборот], кто представит сутру подразумеваемого смысла как сутру прямого смысла - тот выскажет ложное суждение о Благословенном“ [Anguttaranikāya Atțhakathā: 2.118.]».

${ }^{6}$ Нагарджуна, видимо, имеет здесь в виду слова Будды:

«Две истины поведал совершенный Будда: обычную и высшую, - а третьей не ухватишь»
Те, кто не понимает различия между этими уровнями бытия, -

не понимает глубокой реальности (tattvam), открытой Буддой.

Без опоры на обыденное, высшее

(paramārtha) не постигнуть,

не достигнув высшего, не достичь и нирваны».

[Nāgārjuna. Mūlamadhyamakakārika 24. 8-10].

Другими словами, нирвана достигается путем духовной практики, приводящей к непосредственному восприятию пусто$m b l$, что позволяет постичь сущность бытия - «таковость», татхату. Татхата (также дхармадхату и т. п. - хотя у разных буддийских мыслителей эти термины получают несколько различное смысловое наполнение) - это своего рода онтологический коррелят nycmomы как всеобщей взаимозависимости.

\section{Основная часть}

Квантовый мир в интерпретациии Эверетта-Менского

Буддийское представление о «двух истинах» (двух уровнях реальности) неожиданно оказалось в целом удивительно похожим на одну из современных интерпретаций квантовой механики. В этой связи в 2010 г. Центр восточных философий Института философии РАН (ИФ РАН) совместно с Центральным Калмыцким буддийским монастырем «Геден Шедуп Чойкорлинг» (г. Элиста), Центром тибетской культуры и информации (г. Москва) и журналом «Буддизм России» провёл конференцию в формате «круглого стола» на тему: «Роль сознания в природе: научные и буддийские представления».

Докладчиками были Б. Алан Уоллес (B. Alan Wallace), президент Института изучения сознания (г. Санта-Барбара, США) и М. Б. Менский, д-р физ.-мат. наук, профессор, главный научный сотрудник Физического института им. П. Н. Лебедева РАН (г. Москва, Россия).

duve saccāni akhāsi sambuddho vadatạ̣ varo

sammutim paramatthañ ca tatiyaṃ nūpalabbhati

Они повторены в нескольких суттах Anguttaranikāya Aț̣hakathā: 1.54; Kathāvatthu Aț̣hakathā: 34; Dīghanikāya Aț̣hakathā: 1.251252; Saṃyuttanikāya Aț̣hakathā: 2.77 (цит. по: [Karunadasa 2014: 319]). 
В обсуждении приняли участие директор Института мировой культуры МГУ академик РАН В. В. Иванов, директор Института мозга человека, член-корреспондент РАН С. В. Медведев, верховный лама Калмыкии Тэло Ринпоче, зам. главного редактора журнала «Успехи физических наук» академик О. В. Руденко, научный руководитель ИФ РАН академик В. С. Стёпин, профессор Д. И. Дубровский, д-р филос. наук В. Г. Лысенко, главный редактор журнала «Буддизм России» А. А. Терентьев. Вёл круглый стол академик В. А. Лекторский. Речь на этой конференции шла об интерпретации Эверетта ${ }^{7}$ в её «расширенном» варианте, предложенном российским физиком М. Б. Менским и о её близости буддийским представлениям о мире.

Интерпретация Эверетта базируется на парадоксе измерения в квантовой механике, который состоит в следующем:

1) микрообъекты, например, элементарные частицы и атомы, существуют вероятностно: можно сказать, что они находятся одновременно во многих точках пространства, с вероятностью отличной от нуля. Но вероятность здесь носит не эпистемологический характер - как характеристика нашего незнания подлинного местонахождения микрочастицы, а онтологический — то есть, частица реально не находится в каком-то одном месте, а пребывает ОДНОВРЕМЕННО во всех местах, где вероятность её местонахождения больше нуля. Это доказано экспериментально и является общепризнанным фактом в физическом сообществе;

2) но что происходит во время измерения, то есть, когда «измеряемая» частица попадает в фотопластинку и оставляет на ней свой след? Видя этот след, экспериментатор должен признать, что «вероятностное» бытие частицы закончилось, ибо по следу частицы, оставленному на пластинке, мы можем определить её местонахождение во время удара по пластинке однозначно.

В этом-то и состоит парадокс: как можно принять, что частица, которая по своей природе существует лишь вероятностно, вдруг теряет эту свою природу, и по крайней мере в какой-то момент ведёт себя не как квантовый объект, а как привычный для нас макро-объект? Что это с ней случилось,

\footnotetext{
${ }^{7}$ См., например: [Менский 2005].
}

когда она врезалась в атом фотопластинки? Ведь столкновение с другими атомами или частицами - это основной способ существования микрочастиц, они, насколько нам известно, больше ничем и не занимаются кроме как летают да сталкиваются со всем, что на пути. И пребывают при этом в вероятностном облике. Как объяснить, что тут вдруг она повела себя наперекор своей природе и «сжалась» в точку?

На первый взгляд, нам, нефизикам, кажется, что

1) по логике так не должно быть, а также, что

2) эту проблему можно просто проигнорировать - нас она не касается. Пусть физики сами разбираются.

Но вспомним, что на самом деле всё вокруг, включая нас самих, состоит из микрообъектов, а это значит, что разрешение данного парадокса необходимо для понимания реальности, в которой мы живём. Яркой иллюстрацией факта связи микро- и макро-мира является мысленный эксперимент Шрёдингера с котом. Шрёдингер мысленно посадил кота в ящик и дал ему в зубы ампулу с ядом, подсоединённую к детектору, способному уловить продукт распада некоего нестабильного атома, и, если атом распадётся, разбить эту ампулу. Но! По науке, этот атом, находящийся в состоянии $A$, когда он не распался, или в состоянии $B$, когда он уже распался, будучи микроскопической, то есть квантовой системой, должен находиться в суперпозиции ${ }^{8}$ состояний $A+B$. Суперпозиция здесь является суммой двух состояний: первое описывает нераспавшийся атом (и живого кота), а второе распавшийся атом (и мертвого кота).

Как это понимать? Почему при открытии ящика мы видим не суперпозицию, а или живого, или мертвого кота? Это, в действительности, тот же самый вопрос, которым мы уже задавались, увидев след частицы на фотопластинке - просто Шрёдингер показал, каким образом он касается и событий нашего макро-мира.

Интересно, что мало кого из физиков этот вопрос интересует. Дело в том, что научные расчёты процессов в микромире

${ }^{8}$ Суперпозиция - принцип в физике и математике, описывающий наложение, суммирование процессов (например, волн). 
не зависят от философских интерпретаций, стало быть, о них практически можно не думать. Однако широко мыслящие корифеи физики, конечно, не обходили эту проблему стороной. Первая интерпретация ей была дана в Копенгагене, где работал Нильс Бор, и обычно её так и называют - копенгагенской.

М. Б. Менский поясняет её следующим образом: «Принимается, что квантовая механика линейна. Это значит, что состояния квантовой системы можно складывать друг с другом $<\ldots>$ и что при любой эволюции квантовой системы (в том числе при измерении) сумма некоторого числа состояний переходит в сумму такого же числа слагаемых (хотя каждое слагаемое может измениться). Это радикально отличается от простой картины измерения, согласно которой после измерения остается лишь одно из этих слагаемых - то, которое соответствует результату измерения. Такая, казалось бы, естественная картина измерения (называемая картиной редукции, или коллапса волновой функции) несовместима с линейностью квантовой механики» [Менский 2010: 114]. Тем не менее в копенгагенской интерпретации, неожиданную и необъяснимую утрату линейности, коллапс волновой функции принимают как непонятный, но факт.

Новый этап поисков - рассказывает М. Б. Менский - начался в 1957 г., когда американский физик Хью Эверетт предложил интерпретацию квантовой механики, впоследствии названную многомировой [Everett 1957]. В ней признается параллельное существование набора классических картин мира (эвереттовских миров), которые лишь в совокупности адекватно представляют состояние квантового мира. То есть настоящее состояние мира - cуперпозищия всех классических картин. Как же это согласуется с повседневным опытом, в котором существует лишь одна картина мира? Ответ Эверетта состоит в том, что частные «срезы» выделяются в «целом» квантовой реальности сознанием наблюдателя, так что субъективно он видит лишь один из классических миров. ${ }^{9}$ При этом каждая из

${ }^{9}$ Пересказано мной по: [Менский 2010: 113]. Далее М. Б. Менский поясняет: «Разные эвереттовские миры нельзя представлять себе как классических альтернатив (или «эвереттовских миров») объективно существует как компонент суперпозиции, но не реальна в том смысле, что выглядит для находящегося в ней наблюдателя как ВСЯ реальность, в то время как ВСЯ реальность - это невозможная для нашего, «классического» мировосприятия суперпозиция всех классических альтернатив.

Такой поворот темы переводит проблему в совершенно новую плоскость, с микрочастиц на сознание. Но на каком основании сделан вывод о том, что классические альтернативы разделяет сознание наблюдателя?

Вернёмся к примеру с котом. Как поясняет Менский: «... открыв ящик, мы, разумеется, никакой суперпозиции не обнаружим, а увидим либо живого кота (и еще не распавшийся атом), либо мертвого кота (и уже распавшийся атом). Описание системы зависит от того, открыли мы ящик или еще не открыли. В более общих терминах, описание системы после измерения зависит от того, осознал ли наблюдатель результат измерения или нет (в случае шрёдингеровского кота измерением можно считать всю описанную процедуру, а результатом измерения - то, что наблюдатель видит, открыв ящик).

А как описать состояние, в котором система находится после измерения? Оказывается, это опять зависит от сознания наблюдателя. Если экспериментатор еще не посмотрел на прибор, то он описывает состояние как суперпозицию $\mid \boldsymbol{\phi} 1) \boldsymbol{u} \mid \boldsymbol{\phi} 2)$. Если уже посмотрел, то либо как $|\boldsymbol{\phi}|)$, либо как lф2) (в зависимости от того, что именно он увидел).

Описание состояния системы зависит от того, осознал ли экспериментатор состояние системы или нет» [Менский 2005: 416 $]^{10}$.

разные материальные миры (иначе при каждом квантовом измерении вместо одного материального мира возникало бы множество похожих миров, чего, конечно, не происходит) - это всего лишь разные классические проекции единственного материального мира, имеющего квантовую природу» [Менский 2010: 115].

${ }^{10}$ Более подробные пояснения этих процессов с точки зрения квантовой механики можно прочитать в переписке автора с (увы, уже покойным) проф. М. Б. Менским [Терентьев 2016]. 
Таким образом, сознание наблюдателя является одним из факторов квантового измерения. М. Б. Менский заключает: «Хотя состояние квантового мира представляется совокупностью многих классических альтернатив, но наблюдатель субъективно воспринимает лишь одну из них $<\ldots>$ остальные для него как бы не существуют. Таким образом, картина единственной классической реальности - это лишь иллюзия, возникающая в сознании наблюдателя» [Менский 2011: 44].

Приехали... Вот уже и физики говорят, что воспринимаемый нами мир - «лишь иллюзия». Будда, конечно, давно это заметил, о чем мы будем говорить далее. А пока что М. Б. Менский делает вывод: «Это значит, что неверным оказывается привычное (в классической физике) представление о том, что свойства, наблюдаемые при измерении, реально существуют еще до измерения, а измерение лишь ликвидирует наше незнание того, какое именно свойство имеет место. При квантовых измерениях это не так: свойства, обнаруженные при измерении, могли вообще не существовать до измерения $<$...> в некотором смысле при квантовом измерении реальность творится, а не просто познается! По сути дела, это означает, что классическое понимание реальности вообще никогда не бывает правильнылм...» [Менский 2005: 418, 419] ${ }^{11}$.

Совершенно верно, соглашаются буддисты, реальна только пустота, то есть взаимозависимое возникновение и взаимозависимое существование всех и вся. Вне взаимодействия бессмысленно говорить и об отдельных вещах и об их свойствах ${ }^{12}$.

11 Эту позицию всегда и защищала мадхьямака. А выделенная курсивом часть фразы дословно совпадает с высказыванием Candrakīrti в Madhyamakāvatāra, 6.31 .

12 Вообще тему паралеллизма некоторых идей современной квантовой механики и буддизма разрабатывают и со стороны физики, и со стороны буддизма: см., напр.: [Zeilinger 2003; Smetham 2017] и др. Об этом говорил и сам Нильс Бор, который был знаком с идеями мадхьямаки через датского переводчика Нагарджуны Пола Туксена [Poul Tuxen 1880-1955] (Благодарю проф. Кр. Линдтнера за эту устную информацию, полученную им от сына проф. Туксена).
Ключевое же развитие идей Эверетта Менским состоит в следующем:

«В формулировке „альтернативные классические реальности разделяются сознанием наблюдателя“" два ключевых понятия, „разделение альтернатив“" и „сознание“, точно не определены <...> автором предложена Расширенная концепция Эверетта (РКЭ), в которой эти два понятия отождествляются: разделение альтернатив = сознание <...> Таким образом, в РКЭ предполагается, что сознание $<\ldots>$ - $>$ это способность человека воспринимать альтернативные классические реальности раздельно» [Менский 2011: 43] $]^{13}$.

Так Менский делает еще один шаг к чисто буддийскому видению реальности: мир, то есть квантовый мир (= суперпозиция = maтхата) и классические альтернативы (миры Эверетта $=$ самврити), - един.

В буддизме это положение формулируется как тождество сансары и нирваны, где «суперпозиция» соответствует таким понятиям, как парамартха, татхата, дхармата, дхармадхату, дхармакая и т. п., а «классические альтернативы» — вьявахара, самврити, сансара.

Важно подчеркнуть, что и то, и другое включает какую-то форму сознания. Менский, определяя обычное бодрствующее сознание как «разделение альтернатив», отождествляет его лишь с явленным миром - нашей «классической альтернативой». Понятно, что нечто исходное для «разделения альтернатив» должно существовать и в «целом» - в суперпозиции. М. Б. Менский этот «сознающий аспект» суперпозиции условно называет «сверхсознанием»: «Сверхсознание - это выход из разделенных классических альтернатив в единый квантовый мир...» [Менский 2010: 117].

Аналогичное понятие существует и в буддизме: дхармадхату имеет «четыре сино-

13 Разумеется, выдвигая такое положение, М. Б. Менский вовсе не претендует на то, чтобы зачеркнуть многотысячелетнюю историю изучения сознания. Он не подменяет понятие сознания своим новым определением, а совершает нечто вроде математической операции, лишь добавляя новое измерение понятию сознания, в рамках принципа монизма - «тождества бытия и мышления», и не претендуя на то, чтобы трактовать его материалистически, спиритуалистически или иначе. 
нима: дхармакая и прочие (Татхагата, высшая истина и нирвана)» [Майтрея 2017: 41].

Татхагата - это один из эпитетов Будды, поэтому мы можем сказать, что в сознающем аспекте дхармадхату (= «суперпозиция») эквивалентен состоянию Будды, а также Знанию (то есть всеведению) Будды.

И, как уточняют махаянские философы, к дхармадхату относится скорее термин Знание (санскр.: джняна), а к сансаре - сознание (виджняна), расщепление «абсолютного» знания под влиянием неведения ${ }^{14}$.

Глубокое отличие буддийского подхода к тому, что здесь было названо «сверхсознанием», состоит в том, что понятие о высшей истине, состоянии Будды, Татхагате и других аналогах «сверхсознания» является не просто результатом логического вывода, как в работе Менского. Напротив, всё содержание, весь смысл буддийской теории и практики и состоит в том, что буддийский йогин работает над своим обыденным сознанием, преобразуя его вплоть до реализации «со-Знания Будды» - подобного тому, что Менский называл «сверхсознанием» суперпозиции.

Дискуссия о «двух истинах» в тибетской философии

Абсолютную и относительную истины в буддизме вообще и в тибетском буддизме в частности не все понимают одинаково. Две наиболее распространённые трактовки этого вопроса в Тибете представлены фигурами философов XV в. - Цонкапой, основоположником школы гелуг, и горампой Сонамом Сенге ${ }^{15}$ из школы сакья.

Сопоставление соответствующих представлений Цонкапы и Горампы лучше всего, на мой взгляд, было сделано в книге тибетского учёного Сонама Такчо [Thakchoe $2007]^{16}$, далее мы в основном будем следовать его линии рассуждений.

${ }^{14}$ См. подробнее: [Ранджунг 2008].

15 Горампа - учёное звание. Однако применительно к знаменитому Сонаму Сенге оно превратилось в прозвище, и в тех случаях, когда собственное имя этого учёного опускается, титул «Горампа» мы будем писать с большой буквы.

${ }^{16}$ Автор не только изучил целый пласт сложных тибетских текстов разных школ, но также сумел выявить философские истоки воззрений их авторов и дать их интерпретацию и оценку на современном философском языке.
Автор начинает свой анализ с того, что задаётся фундаментальным вопросом: а что, собственно, разделяется на «две истины». Итак, о чем, собственно, речь? Что считают тибетские буддисты реальностью, выступающей в форме «двух истин»?

Джамьян Шепа находит вне школы гелуг шесть различных мнений об этом [Thakchoe 2007: 9], но центральное место в истории тибетской философии занимают два: уже упомянутые воззрения Цонкапы и Горампы. С. Такчо указывает на корень их расхождений: в сущности, оппоненты говорят о разных реальностях. Для Цонкапы это объективная реальность, если так можно хотя бы условно назвать сферу познаваемого (тиб.: shes bya), а для Горампы это «только ум» (тиб.: blo tsam). То есть на «две истины» - на два уровня существования - ими делятся разные вещи. Понятно, что и всё последующее у обоих мыслителей радикально отличается.

Цонкапа в обосновании своего подхода опирается, в частности, на «Питапутра-самагама-сутру», где сказано:

«... Татхагата понимает и эмпирическое (тиб.: kun rdzob) и высшее (тиб.: don dam), потому что объекты познания полностью содержат и относительный, и высший уровень» (цит по: [Thakchoe 2007: 10]).

При этом он полагает, что речь тут идёт не просто о двух разных эпистемологических подходах, а о том, что все объекты реально имеют две природы - относительную и абсолютную (подобно явлению и сущности, добавил бы я. - A. T.): обе есть в каждом явлении, но выявляются в зависимости от свойств познающего сознания. «Сущность является», как говорил Гегель.

Горампа же, выделяя четыре основания деления на две истины «просто ум; просто взаимозависимость; просто объекты познания; просто субъекты, которых учил Будда» - понимает все эти основания преимущественно субъективно (эмпирические объекты познания для него - это конструкции ума) и поясняет: «Хотя в способе существования (тиб.: gnas tshul) объекта нет двух истин/уровней, они выделяются умом, видящим [истинный] способ существования, или не видящим [истинный] способ существования» [Thakchoe 2007: 13]. 
С. Такчо подводит итог этому предварительному обзору, заключая, что с точки зрения Горампы «...разделение на два уровня/истины не может быть онтологически обосновано, поскольку есть лишь одна реальность» [Thakchoe 2007: 13]. Но невежды видят лишь явления, а мудрые - лишь сущность. И, по мнению Горампы, разделение реальности на два уровня нужно лишь в пропедевтических целях, на самом деле «естина» одна - абсолютная; а относительная — просто заблуждение.

Интересно, что почти все ведущие тибетские мыслители, кроме Цонкапы, придерживались, как сообщает С. Такчо, такой же позиции: Сакья Пандита, Лонгченпа, Мипхам, Ронгтон Шакья Гьялцен, Такцанг-лоцава, Шакья Чогдэн, Микьо Дорже и Гендун Чойпэл. Так же, по мнению С. Такчо, понимают теорию двух истин и многие современные исследователи, в частности К. Линднер и К. Хантингтон. Сам же Горампа полагал, что такой позиции единодушно придерживались все сватантрики и прасангики Индии [Thakchoe 2007: 15]. ${ }^{17}$

Интересно, что обосновывали свои позиции и Горампа, и Цонкапа на одних и тех же словах Нагарджуны и Чандракирти:

«Сказано [Буддой, что] две природы обнаруживаются во всех вещах -

благодаря обретению подлинного или обманчивого восприятия.

Объект видящих подлинно называется «реальностью» (санскр.: tattvam; тиб.: de nyid),

${ }^{17}$ Однако по крайней мере один из ведущих современных философов школы кагью, Трангу Ринпоче, в этом вопросе стоит на позициях Цонкапы: «Каково соотношение условной и высшей истин? Является ли одна правильной, а другая нет? Нет, между ними нет противоречия. Высшая истина является самой сутью условной истины, в то время как условная истина - способом проявления высшей» [Thrangu 2000: 5]. Также интересно отметить, что это же толкование поддерживается ещё одним общепризнанным столпом махаяны - Асангой. Как отмечал Ф. И. Щербатской: «Согласно Dharmadharmatā-vibhanga (kārika 2) две сущности должны различаться в каждой дхарме: её собственная дхарма-сущность (т. е. сама вещь, паратантра) и её дхармата̄-сущность (т. е. Абсолют, та же самая вещь sub-specie-aeternitatis)» [Stcherbatsky 1936: 23]. а [объект] видящих обманчиво - „относительной истиной“"».

Candrakīrti Madhyamakāvatāra: $6.23 .^{18}$

То есть все вещи имеют эти два аспекта, две природы. На первый взгляд кажется, что здесь всё сказано однозначно, и понимание Чандракирти Цонкапой не может быть оспорено.

Однако Горампа толкует сказанное совершенно иначе. По мнению С. Такчо, причиной этого является меньшая грамматическая определённость тибетского перевода данной шлоки, позволяющая трактовать выражения yang dag mthong ра и mthong ba brdzun ра и как «видящие подлинно» и «видящие ложно», и как «подлинное видение» и «ложное видение».

Такчо говорит: «Приравнивание «подлинного видения» к «видящим подлинно», а «ложного видения» к «видящим ложно» играет решающую роль в определении двух истин у Горампы. Оно позволяет ему утвер-

${ }^{18}$ Санскр.: samyagmrșādarśanalabdhabhāvam rūpadvayam bibharati sarvabhāvāḥ | samyagdriśām yo vișayah sa tattvaṃ mṛșādṛ́saạ̄ saṃvṛtisatyam uktam \|.

Тиб.: dngos kun yang dag brdzun pa mthong ba yis|

dngos rnyed ngo bo gyis ni 'dzin par 'gyur| yang dag mthong yul gang de de nyid de| mthong ba brdzun pa kun rdzob bden par gsungs||

Автокомментарий (Candrakīrti. Madhyamakāvatāra-bhāssya) говорит: «Будды $<\ldots>$ указывали два вида внутренней природы - санскар, ростков и всех других внутренних и внешних предметов, а именно: относительную и абсолютную. Абсолютное как объект мудрости видящих истинно - обнаруживается, а существование, устанавливаемое благодаря «собственной природе» - нет. Это одна природа. Другая - самобытие, воображаемое силой ложного восприятия обычных существ, чей глаз мудрости полностью закрыт катарактой неведения, - такое самобытие не устанавливается восприятием простаков, такого бытия как самобытие нет.

Итак, у всех вещей воспринимаются эти две природы. Та природа из этих двух, которая является объектом истинного видения, - истинная суть. Она называется абсолютной истиной. Таков смысл. Ее собственная сущность и должна объясняться. То, что является объектом ложного видения, - относительная истина...». (Ср.: [Чандракирти 2004: 109]). 
ждать, что настоящей основой для различения двух истин в действительности является противоречие между несогласующимися воззрениями.

Но если бы всё было так просто, достаточно было бы проверить цитату по санскритскому оригиналу, где однозначно написано «видящие» (санскр.: dṛ́śạ), а не «видение» (санскр.: darśaṇa), сказать «прав Горампа, а не Цонкапа» и закрыть вопрос. Однако в действительности всё сложнее: ведь мы не можем уйти от того факта, что всякое восприятие субъективно. Поэтому слова «видение» и «видящий субъект» равно можно понимать и чисто субъективно, спиритуалистически (как делает Горампа) и монистически, то есть не разделяя онтологически субъект и объект восприятия, как делает Цонкапа ${ }^{19}$. То есть выбор интерпретации в данном случае должен определяться не филологическими, а философскими основаниями.

А в философском плане Горампа ещё более проясняет свой взгляд: «Здесь, в системе мадхьямаки, сам объект не может быть разделён на две истины. Эмпирическая истина и высшая истина делятся в рамках способа восприятия как субъект, воспринимающий обманчивое, и субъект, воспринимаюший истинное <...> Все прасангики и сватантрики Индии согласны в том, что [две истины] разделяются постигающим объект умом» [Thakchoe 2007: 68] $]^{20}$.

Но Нагарджуна писал в «Объяснении бодхичитты» о взаимоотношении двух истин несколько иначе:

«Относительное указано как пустое (т. е. абсолютное. - А. T.),

пустое есть только относительное;

[одно] невозможно без [другого] так же,

как произведённое и непостоянное» [Nāgārjuna: Bodhicittavivaraṇa, 68].

C. Такчо напоминает, что, комментируя эту шлоку, Цонкапа подчёркивал: «четверостишие показывает, что вещи как они есть (то есть nустые в абсолютном плане. A. T.), онтологически неотличны от относительного...» ${ }^{21}$. То есть, относительное и аб-

19 С. Такчо, правда, в своей книге считает монистом Горампу, а не Цонкапу — далее я оспорю эту точку зрения.

${ }^{20}$ Цитируется трактат Горампы Nges don rab gsal.

${ }^{21}$ Dgongs pa rab gsal — цит. по: [Thakchoe 2007: 18]. солютное онтологически неотличны: «форма есть пустота, пустота есть форма», говорит нам Сутра Сердца. Однако это не значит, что они полностью тождественны: относительная истина имеет референтом относительную природу объекта, а абсолютная - абсолютную.

Горампа же полностью противоставляет обе истины на эмпирическом уровне и онтологически, и эпистемологически, но при этом оговаривается, что в высшем смысле, то есть в самадхи святого арья, две истины - за пределами тождества и отличия ${ }^{22}$. Ведь, по его мнению, разделяется на две истины лишь познающий ум, и восприятие, базирующееся на неведении, - это относительная истина, а на понимании $n y$ cmombl - абсолютная. Соответственно, то, что воспринимает относительный ум - это иллюзия, наподобие видения больным катарактой «падающих волосков», а то, что воспринимает в самадхи ум арьи - реальность, наподобие здорового зрения, ни видящего никаких «падающих волосков». Понятно, что «падающие волоски» - это просто ошибка восприятия, они не существуют в действительности и не имеют ни онтологической, ни эпистемологической связи с их отсутствием в зрении здорового человека.

Чандракирти характеризовал относительную истину как (1) скрывающую абсолютную, как (2) взаимозависимость и как (3) условное, мирское словоупотребление [Candrakīrti 1906: 492]. Цонкапа и Горампа вновь понимают эти характеристики по-разному.

Относительно (1) Цонкапа считает, что хотя три типа арьев ${ }^{23}$ свободны от неведения, они могут иметь правильное эмпирическое познание относительного - то есть в их восприятии все условные явления не сводятся к безусловной истине. Горампа же, следуя за Джаяанандой, полагает, что после созерцания абсолютной истины в постмедитативном состоянии арьи возвращаются в относительный мир заблуждения и двойственности, где правильное познание невозможно.

${ }^{22}$ Nges don rab gsal. Цит. по: [Thakchoe 2007: 22]. Ещё более полное разделение этих двух уровней реальности, отмечает Такчо, характерно для Долпопы.

${ }^{23}$ То есть, достигшие непосредственного видения пустоты шраваки, пратьекабудды и бодхисаттвы. 
Относительно (2) Цонкапа полагает, что понятие взаимозависимости относится ко всей реальности: и в этом отношении даже высшая истина/уровень бытия относительна, ведь она онтологически неотдельна от мира явлений. «Парамартхасатья - это высшая природа эмпирической реальности», — цитирует С. Такчо Цонкапу [Tsong kha pa 1977: 41] и резонно добавляет: «Ведь если бы парамартхасатья не была обусловленно-возникающим явлением, она стала бы онтологическим абсолютом...» [Thakchoe 2007: 54].

Горампа же убеждён в обратном: абсолютное ни в каком смысле не зависимо или, тем более, «взаимозависимо», ибо взаимозависимость, по его мнению, согласному с мнением Джаяананды, порождается неведением, а абсолютное никак не связано с неведением. Как он пишет в своём комментарии на Мула-мадхьямака-карику:

«...природа реальности <...> имеет три определяющие характеристики, а именно: она не произведена причинами и условиями; она существует независимо от условностей и прочих явлений; она неизменна» [ lta ba'i 'od zer — цит. по: [Thakchoe 2007: 73]).

Здесь его расхождение с Цонкапой радикально: ведь согласно Цонкапе именно взаимозависимость (= пустота) и является сутью высшей истины, и никакой другой высшей истины вне взаимозависимости просто нет и быть не может. Да и не только с Цонкапой, вспомним здесь снова Сутру Сердца: «форма есть пустота, пустота есть форма...». Горампа же понимает абсолютное как нечто полностью трансцендентное миру обусловленности, полностью независимое.

А если вернуться к относительному, то и Цонкапа и Горампа опять подтверждают своё понимание относительного (санскр.: самврити) одним и тем же стихом из Мадхьямака-аватары:

«Поскольку неведение скрывает подлинную природу, оно — „самврити“.

Оно понимает обусловленные явления как истинные $e^{24}$.

24 «Истинные» в этом контексте значит «истинно существующие», то есть существующие самостоятельно, необусловленно. Именно такое существование и отрицается в мадхьямаке, где всё сущее считается пустыл - то есть взаимообусловленным.
Поэтому сказано Муни: „это самврити-сатья“;

и всё обусловленное - самврити» [Candrakīrti Madhyamakāvatāra: 6.28].

Но Цонкапа понимает первую строку этой шлоки ${ }^{25}$ лишь как объяснение, почему возникает самврити, специально подчёркивая, что термин «самврити» здесь и «самврити» в третьей и четвёртой строках - не одно и то же: в первой строке этот термин имеет лишь субъективный аспект и относится только к омрачённому сознанию, а не к относительной истине в целом ${ }^{26}$. Горампа же понимает этот стих прямо противоположно: именно как отождествление неведения и самврити. Текст, как мы видим, позволяет и одно, и другое прочтение, поэтому понимание его должно основываться только на общем контексте мадхьямаки.

Цонкапа считает, что характеристика «заблуждение» недостаточна для определения относительной истины, (или относительного уровня существования) - «если нечто существует на относительном уровне - оно должно удовлетворять критериям эмпирического существования» ${ }^{27}$.

А из определения Горампы, следующего за Джаяанандой, следует вывод, что свободный от неведения арья в самадхи и, тем более, Будда, вообще не видят нашего мира: «Будды не имеют какого-либо восприятия видимых явлений, как, например, синего цвета» [Jayānanda: 73]

По мнению Горампы, Будды видят лишь абсолютное (суперпозицию. - $A$. T.), понимаемое ими как трансцендентная неизменная реальность, что, кажется, не вписывается ни в буддийское воззрение, ни в физику.

Но в интерпретации мадхьямаки неизменность реальности и состоит во взаимозависимом возникновении, то есть неизменности nycmombl, где нет ни рождения, ни исчезновения. Освобождение и есть постижение nycmombl, и Нагарджуна пояснял, что:

25 Санскр.: mohạ̣ svabhāvāvaraṇād dhi saṃvṛtị, Тиб.: gti mug rang bzhin sgrib phyir kun rdzob ste.

${ }^{26}$ Тиб: rkang pa dang pos stan pa'i kun rdzob dang| rkang pa phyi ma gnyis kyis bstan pa'i kun rdzob gnyis gcig tu me bya ste - текст из работы Цонкапы dgongs pa rab gsal; цит. по: [Thakchoe 2007: 56, 194].

${ }^{27}$ Из работы Цонкапы rtsa shes țik chen. Цит. по: [Thakchoe 2007: 57]. 
«Сансара и нирвана не существуют как два [разных объекта].

Совершенное познание сансары и есть сама нирвана!» [Nāgārjuna Yuktișaștīka: 6]

Но как и в какой степени возможно познание высшего уровня реальности? Оба мыслителя рассматривают эту проблему на уже упоминавшемся традиционном индийском примере с больным катарактой, которому видятся «падающие волосы».

Цонкапа считает, что если больному объяснить иллюзорность его видения, это поможет ему лучше понимать действительность, хотя избавиться от видения падающих волос он и не в состоянии. Горампа же считает, что ничего такой человек не поймёт, поскольку речь построена на использовании универсалий (слова (тиб.: sgra spyi) обозначают классы явлений (тиб: don spyi), поэтому принципиально неспособны передать уникальность восприятий).

Цонкапа согласен с ним только отчасти: да, обычные люди неспособны к непосредственному недискурсивному постижению абсолютного. Но получить правильное представление об абсолютном они могут и даже должны, хотя всегда необходимо помнить о различении понимания реальности и самой реальности, которая обычным людям недоступна. Цонкапа говорит:

«Хотя объяснение высшей истины с помощью аналогий и не ведёт к такой её реализации, какую имеют освободившиеся от облаков неведения <...> высшая истина не является и совершенно недостижимой, ибо её глубокий смысл раскрывается словами текстов предельного уровня» ${ }^{28}$.

Следуя этой мысли Цонкапы, С. Такчо вопрошает Горампу: «Если язык был бы совершенно не в состоянии раскрыть высшую истину, <..> а интеллект слушателей совершенно не способен её понять, зачем Будда столько о ней говорил? Да и сам Горампа наполнил несколько томов учениями о высшей истине. Для Горампы и его сторонников это весьма трудный вопрос...» [Thakchoe 2007: 84].

Не думаю, что такой уж трудный. Горампа вполне адекватно отвечал на него, указывая, что Будды «излагают временное учение о высшей истине в условных терми-

${ }^{28}$ [Thakchoe 2007: 84]. Цитата из dgongs pa rab gsal. нах, используя «лингвистическое наложение» (тиб.: sgro brtag; санскр.: samāropa) ${ }^{29}$ [Thakchoe 2007: 84], так же, как и Чандракирти:

«Ведь Бхагаван говорил: „Как может невыразимая истина преподаваться или изучаться?...только через особое употребление обычного языка (самаропа)“” [Candrakīrti 1906: 264].

Теперь остановимся на дискуссии, которая возникла по поводу понимания высшей истины - это один из важнейших пунктов полемики школы гелуг с её оппонентами. Исследователь воззрений Горампы Хосе Кабезон пишет: «Для Цонкапы объектом аналитического (conceptual) понимания $n y$ cmombl является действительная высшая истина. <..> Иначе говоря, для Цонкапы и логический вывод, и йогический гносис (санскр.: jñāna) постигают один и тот же объект - nycmomy - хотя и разными способами. Для Горампы - исключительно йогический гносис, неаналитический и нерассудочный способен постигать подлинное высшее» [Cabezón et al. 2007: 52.]

То есть позиция Цонкапы, по словам Горампы, такова:

«Простое отрицание такой истины [то есть, независимого истинного существования. - $A$. T.], которая не обнаруживается посредством анализа, объяснённого в текстах мадхьямаки, - и ЕСТЬ пустота. Это неутверждающее отрицание ${ }^{30}$ и есть высшее воззрение мадхьямаки; это действительная (mtshan nyid pa) абсолютная истина (don dam bden ра) и высшая реальность (gnas lugs mthar thug ра) явлений» [Cabezón et al. 2007: 81,115].

29 В «Принстонском словаре буддизма» samāropa определяется как «superimposition», «reification», или «erroneous affirmation»; приписывание объекту качества, которым он фактически не обладает [The Princeton Dictionary of Buddhism 2013: 746].

30 Этот термин требует некоторых пояснений. «Утверждающее отрицание» (санскр. pariccheda; тиб. ma yin dgag) - это логическое отрицание, подразумевающее, что если ложно А, то истинно не-А. «Неутверждающее отрицание» (санскр. viccheda; тиб. med dgag) подразумевает, что из отрицания А не следует признание не-А или чего бы то ни было, а только лишь (тиб.: tsam) отрицается А. 
и далее:

«Все [ответвления] великой и малой колесниц одинаковы в том, что они реализуют пустоту - простое отрицание истины, - как объяснено выше» [Cabezón et al. 2007: 87$]^{31}$.

Но действительно ли Горампа правильно понял позицию Цонкапы, якобы coстоящую в том, что nycmoma или высшая истина - это всего лишь «неутверждающее» логическое отрицание ошибочных представлений? Приведу лишь несколько примеров того, что сам Цонкапа говорил по этому поводу в своих основных работах. Например, в «Большом руководстве к этапам Пути Пробуждения» он одобрительно приводит мнение Камалашилы:

«... в «Свете срединности» сказано, что постигаемое с помощью логики называется «абсолютным» [лишь] по сходству с абсолютной истиной, [но не является им]» [Цонкапа 2010: 937].

Абсолютная истина, говорит Цонкапа далее, это нирвана, а не что-то, постигаемое логически:

«...достижение нирваны означает ее осуществление, нирваной же полагается факт прекращения [страдания], то есть абсолютная истина» [Цонкапа 2010: 1043].

и подкрепляет это цитатой из Чандракирти: «... абсолютное не становится ни вещью, ни отсутствием вещей: ибо [абсолютное] - это естественный покой» [Цонкапа 2010: 1045].

Чисто гносеологические определения абсолютной истины как отсутствия за-

31 Здесь Кабезон мягко отмечает (прим. 91 на c. 292), что «позиция Цонкапы чересчур упрощена Горампой». Я бы сказал - полностью искажена, - что будет видно из приводимых ниже материалов. Кроме того, здесь очередной раз необходимо отметить неудачный перевод тибетского слова bden pa как truth ('истина'): он совершенно искажает смысл слов Горампы. В действительности, Цонкапа, по мнению Горампы, говорит, что «nустота - это просто отрицание истинного (то есть независимого, постоянного. - А. Т.) [существования]», а не нелепое «nустота это просто отрицание истины», — как переводит Кабезон. блуждений встречаются у Цонкапы лишь контекстуально, в полемике против оппонентов, верящих в «собственную сущность» вещей:

«Итак, абсолютная истина определяется просто как (1) отсутствие каких-либо измышлений о вещах, „определяемых собственной сущностью“, и (2) избавление тем самым от всех измышлений ложного видения самобытия, которого нет. И в „Ясных словах“ (15.2) сказано:

„Благодаря тому, что святые не имеют катаракты неведения и не видят того, что воспринимается из-за катаракты незнания [истинного] порядка вещей, объектом их [познания] становится сущность (санскр.: svarūpa), которая определяется как [подлинная] природа (санскр.: svabhāva) [вещей]“» [Цонкапа 2010: 1046] ${ }^{32}$.

«Те, кто, не считает абсолютную истину лишь полным пресечением двух самостей и прочих фантазий, <..> отстраняются от всего Слова Большой и Малой колесниц» [Цонкапа 2010: 1046].

Здесь Цонкапа полемизирует против тех, кто представляет абсолют как нечто отдельное, самосущее, всплывающее тогда, когда все видимости устранены. Поэтому он и направляет острие своей критики против гипостазирования такого абсолюта. Но это он делает лишь для нужд такого рода полемики. Целиком же понятие абсолютной истины Цонкапа разбирает в своей последней большой работе - «Среднем Ламриме», где он пишет:

«абсолютной истиной считается высшая реальность $<\ldots>$ в ,Толковании ' 60 доводов "“ [Чандракирти] (комм. на шлоку $5 \mathrm{~cd}$. - A. T.) говорит, что абсолютная истина считается существующей лишь в мирском, условном смысле ${ }^{33} \gg$ [Цонкапа 2015: 509].

И далее Цонкапа делает ключевое пояснение своей позиции:

32 Такой природой является пустота.

33 Тиб.: "jig rten gyi tha snyad, санскр.: lokavyavahāra, общепризнанное словесное обозначение. Он имеет в виду, что её нельзя гипостазировать как некую трансцендентную реальность. 
«Истинное познание двояко: (1) недискурсивное знание (ye shes) святых при нерассудочном ровном сосредоточении; (2) дискурсивное истинное познание при вникании в реальность, опирающемся на аргументы (rtags), и т. п.

Недискурсивное Со-Знание (ye shes) и схожая с ним мудрость (shes rab), указанные в „Пламени диалектики“ [Бхавивеки. - A. T.] в качестве абсолютного, и два [типа] абсолютного, упомянутые в „Свете срединности“" [Камалашилы. - $A$. T.], означают одно и то же. Поэтому неправильно полагать, что два [типа] абсолютного, упомянутые в этом сочинении, означают лишь абсолютную [истину] в качестве объекта, но не субъекта.

Первый [тип - недискурсивное Со-3нание], постигающее реальность, способно одновременно пресечь измылиленное [представление об] истинности и двойственное видение по отношению к своим объектам, поэтому является подлинным абсолютным, а также называется „ушедшим за пределы всех измышленных [понятий]“".

Второй [тип - дискурсивная мудрость] может прекратить представление истинными своих объектов, но неспособен пресечь двойственное видение. Поэтому, будучи лишь схожим с немирским абсолютным, он [и называется] „сходным с абсолютным“.

Необходимо выделить и два типа абсолютного объекта (yul gyi don dam), опровергающие абсолютное возникновение и т. п. форм и прочего.

(1) Пустота объектов, истинно познанная недискурсивным путем, является подлинным абсолютным, незатемненным обоими измышлениями ${ }^{34}$.

(2) [Пустота объектов], истинно познанная дискурсивным способом, затемнена ещё одним измышлением ${ }^{35}$, поэтому не является подлинным абсолютным, не затемнённым ни одним из двух измылилений...» [Цонкапа 2015: 527].

Таким образом, можно видеть, что критика Горампы, приписывающая Цонкапе мнение о том, что высшую реальность

34 Т. е. представлением об истинном существовании (тиб. bden 'dzin) и двойственным видением (тиб. gnyis snang).

35 T. е. двойственным видением. можно полностью постичь логически, основана на заблуждении - такого мнения у Цонкапы нет. Дискурсивное познание, как Цонкапа и говорит в вышеприведенных цитатах, дает представление о высшей истине, но это только «подобие» (тиб.: rje su mthun pa) истины, а не сама истина. Если Горампа и нашёл где-то в трудах Цонкапы высказывание, которое он интерпретировал в ином смысле - он должен был сверить его с контекстом и с мыслями Цонкапы, представленными в его основных трудах.

Глубже вопрос о понимании абсолютной истины в трудах Цонкапы уже давно разобрал геше Туптен Джинпа в своей книге о философии Цонкапы:

«... согласно Цонкапе, термин „высшее“ (paramārtha) используется двумя способами <...> Во-первых, и прежде всего, в контексте онтологии мадхьямаки (или её отрицания), термин „высшее“ означает, что все вещи и события лишены какого-либо абсолютного или высшего существования или тождественности. <...> Во втором случае „высшее“ соотносится с „относительным“ (samvrrti) в общемахаянской доктрине двух истин. В этом, последнем, контексте „высшее“ относится к высшей природе всех вещей и событий в отличие от их относительной (то есть эмпирической и условной) природы. Цонкапа пишет: „Если это [различие между двумя значениями термина „высшее“] хорошо понято, будет понятен смысл объяснения, почему нет противоречия между [утверждением,] что ничто не существует по своей собственной природе и ничто не существует с высшей точки зрения, сохраняя при этом [позицию,] что высшая природа существует и является способом существования [вещей (как они есть. A. T.)] и высшего объекта“» [Jinpa 2002: $46-47]^{36}$.

«...Поэтому не может быть, чтобы высшее значение, природа вещей, их $m a$ ковость, способ существования [всех явлений] не существовали. Но, если они

${ }^{36}$ Цитата из $d B u$ ma la 'jug pa'i rnam bshad dgongs pa rab gsal: 'di legs par shes na gshis lugs la dang/ don dam du med zer ba dang/ yang chos nyid yod par 'dod cing de nyis gshis lugs dang don dam yin par smra ba mi 'gal ba'i gdnad rnams shes par 'gyur ro// 
существуют, - то не как абсолютные, или [имеющие свой особый] реальный способ существования. Предположить противное - значит показать полное незнакомство с методами критического анализа с высшей точки зрения» [Jinpa 2002: 46-47]. ${ }^{37}$

Горампа, видимо, не читал данные произведения Цонкапы и составил своё понимание его идей лишь на текстах, где использовался только первый из двух смыслов термина «высшее». Но удивительно, что и некоторые глубокие знатоки произведений Цонкапы следуют пониманию Горампы. Так, Хосе Кабезон пишет: «Для Цонкапы действительная высшая истина является объектом логического (conceptual) понимания пустоты» [Cabezón et al. 2007: 52]. Это мнение тоже апеллирует лишь к первому значению слова «высшее» в понимании Цонкапы и совершенно игнорирует второе.

${ }^{37}$ de'i phyir don dam dang chos nyid dang de kho na nyid dang gshis lugs rnams med par mi 'thad la/ yog na 'ang de dag tu ma grub na gzhan gang du grub ces smra ba ni don dam par grub rna grub dpyod pa'i dpyod lugs kyi rnam pa rna chags pa'i gtam $\mathrm{mo} / /$

Отметим, что данный подход Цонкапы в точности соответствует подходу Нагарджуны, о котором Д. С. Рюэгг писал: « В приписываемых ему работах, в действительности, мы находим и негативную теорию, пользующуюся апофатическим методом, и позитивную теорию с катафатическим представлением парамартхи <...> Негативная и позитивная теории абсолютной реальности, использовавшие апофатический и катафатический подходы для её описания, часто трактуются как противоположные доктрины. Для некоторых тибетских комментаторов различия между ними оказалось корнем противостояния между доктринами о пустоте самобытия (rang stong) и доктриной о пустоте лишь разнообразных факторов, НЕ конституирующих абсолют (gzhan stong)...Возможно, стоит подумать, не являются ли оба эти подхода, не согласующиеся на литературном уровне (где гимны могут контрастировать со схоластическими трактатами), - взаимодополнительными на философском и религиозном уровнях (где обе теории, хотя и отличны, но не обязательно несовместимы. Это соответствовало бы базовой махаянской теории о том, что высшая реальность невыразима в словах и понятиях и может быть познана лишь прямо и непосредственно, за пределами викальп и прапанч» [Ruegg 1981: 43-44].
На такую ошибку указывал ещё в XIX в. Жамар Ринпоче:

«Ранние [учители] считали Славного Чандру, Шантидеву и других «мадхъямиками[-приверженцами] непребывания», полагающими абсолютной истиной лишь устранение всех измышлений относительно явлений. Они неправильно понимали такие слова, как изреченные во „Введении в практику“ (Шантидевы. A. T.):

Когда для ума нет ни сущего, ни не-сущего,

тогда отсутствуют и другие представления, -

поэтому [ум], не имея объекта, совершенно спокоен.

И, по их мнению, система „,[приверженцев] непребывания“" состоит в следующем. При [постижении] неописуемой абсолютной [истины], для которой не подходят никакие измышленные понятия: „сущее“, „не-сущее“, оба вместе и ни то, ни другое $<\ldots>$, — в уме отсутствуют любые представления. Это лишь называется „постижением отсутствия измылилений“, но по сути дхармата выходит за пределы объектов ума, поэтому и ровное сосредоточение арьи не имеет объекта.

Так следует понимать ,лишь устранение измылилений“ в этой системе. Но важно знать, что оно не имеет ничего общего с простым опровержением отрицаемого истинного существования и сосредоточением на лишенной всех измылилений абсолютной [истине] в состоянии недискурсивного постижения nустоты»» [Zhamar 2012: 365-366].

Однако вернёмся к другим аспектам двух истин. Тесно связан с проблемой возможности постижения абсолютной истины вопрос об одном из краеугольных камней буддийской практики - «правильном воззрении»: как достичь его? Оно, соответственно двум истинам, разделяется на два уровня: мирское (санскр.: laukika-saṃyagdṛști, тиб.: 'jig rten pa'i yang dag pa'i lta ba) и «надмирское» (санскр.: lokottara-samyagdṛțti, тиб.: “jig rten las 'das pa'i yang dag pa'i lta ba). Первое — это умозрительное постижение четырёх истин, второе - переживание их тоже на относительном уровне, но в собственном непосредственном опыте, «проникая, трансцендируя 
и непосредственно открывая надмирскую природу внутри себя» [Thakchoe 2007: 94]. Надмирское становится возможным и начинается с пути видения - вместе с непосредственным постижением nycmombl.

Понятно, что относительно мирского воззрения у Цонкапы и Горампы разные мнения. Для Цонкапы мирское правильное воззрение связано с обеими истинами, поскольку они неразделимы; мирское правильное воззрение предшествует и подготавливает путь надмирскому, являясь условием его возникновения:

«Если бы не так, то и неомраченный путь не мог бы возникнуть из омраченного. Следовательно, простые существа не достигали бы святости, поскольку причина и результат не схожи» [Цонкапа 2010: $1251]^{38}$.

Для Горампы мирское правильное воззрение связано исключительно с относительной истиной, поскольку, по его мнению, оно неразрывно связано с верой в «истинное» существование. На абсолютную истину направлено только надмирское правильное воззрение, а мирское «правильное воззрение» лишь мешает в этом.

Интересно, что, характеризуя эту позицию Горампы, Такчо приводит слова индийского исследователя Нарайна, правильно указывающего, что при таком толковании относительной истиньл «сансара и нирвана оказываются двумя реальностями (orders), не только совершенно разорванными и невзаимодействующими, но и непроницаемо автономными, что сводит мадхьямика к статусу бескомпромиссного дуалиста» [Narain: 239]. Но сам Такчо, как ни странно, приходит к прямо противоположным выводам, и характеризует Горампу как мониста, а Цонкапу - как плюралиста [Thakchoe 2007: 2].

На мой взгляд, именно осознание тождества относительной и абсолютной реальности является монистическим подходом, поэтому последовательным монистом является как раз Цонкапа.

38 Любопытно, что аналогичную мысль Н. Бора упомянул В. Гейзенберг в своей автобиографии: когда они уезжали из горной хижины, где катались на лыжах, Бор мыл посуду и заметил, что вода, которой он мыл посуду, довольно грязная, мочалка грязная, но результат довольно удовлетворителен...

\section{Заключение}

Взгляд на тибетский спор с позищий квантовой физики

Характерной чертой квантового мира является то, что все события в нем являются взаимоопределяемыми. Т. е. суперпозищия - это истинное положение вещей, где нет отдельных сущностей, обладающих собственной природой, а все существует только взаимоотносительно.

Такое истинное состояние дел, состояние взаимозависимого возникновения, в буддизме называется пустотой или таковостью - «татхатой». Человек, который достиг уровня арья, т. е. непосредственного постижения nycmombl, или татхаты, уже не видит отдельные вещи и явления, которые видим мы. А что он видит? Он видит парамартху - абсолютную истину, или, как сказал бы физик - суперпозицию, т. е., метафорически говоря, все явления всех вероятностных классических «миров Эверетта» одновременно в их взаимосвязях ${ }^{39}$.

А кто прав с точки зрения интепретации физики Эверетта-Менского - Цонкапа или Горампа? Если абсолютная истина (парамартха, татхата), подлинная реальность дхармадхату подобна тому, что у физиков именуется «суперпозицией», а относительная истина (самврити, вьявахара) - «классической альтернативой», то, как было сказано (см. выше) М. Б. Менским, «картина единственной классической реальности это лишь иллюзия, возникающая в сознании наблюдателя». Но иллюзорно только наше восприятие этой реальности как единственной - в действительности «состояние квантового мира представляется совокупностью многих классических альтернатив», воспринимаемых разными наблюдателями, сознание которых по-разному кармически (как сказал бы буддист) обусловлено. То есть, с точки зрения квантовой интерпретации Эверетта-Менского, и классические

${ }^{39}$ Подчеркну еще раз, что это только условное, метафорическое (физик сказал бы «классическое, а не квантовое») выражение: отдельных «миров» или отдельных явлений ни в татхате, ни в суперпозиции просто нет. Как выглядит татхата или совокупность всех миров Эверетта - представить себе на нашем, относительном, «классическом» уровне бытия невозможно. 
альтернативы (мир явлений), и суперпозиция (сумма всех миров Эверетта, квантовый мир) существуют объективно, хотя и расщепляются - при расщеплении Знания в воспринимающих сознаниях. Поэтому думаю, что в этом вопросе физики одобрили бы понимание Чандракирти Цонкапой, а не Горампой.

\section{Источники}

Candrakīrti - Candrakīrti. Madhyamakāvatāra. D3861 ${ }^{40}$.

Candrakīrti - Candrakīrti. Madhyamakāvatārabhāṣya. D3862.

Jayānanda — Jayānanda. Madhyamakāvatārasyațīkā. D3870.

Nāgārjuna — Nāgārjuna: Mūlamadhyamakakārika. Nāgārjuna - Nāgārjuna: Bodhicittavivaraṇa.

Nāgārjuna — Nāgārjuna: Yuktișaștịika.

\section{Sources}

Candrakīrti. Madhyamakāvatāra. D3861 ${ }^{41}$.

Candrakīrti. Madhyamakāvatāra-bhāsya. D3862. Jayānanda. Madhyamakāvatārasyațīkā. D3870.

Nāgārjuna. Bodhicittavivaraṇa.

Nāgārjuna. Mūlamadhyamakakārika.

Nāgārjuna. Yuktișașțīka.

\section{Литература}

Гегель 1971 - Гегель Г. В. Ф. Наука логики. T. II. М.: Мысль, 1971. 248 с.

Даль 1880 - Даль В. И. Толковый словарь живого великорусского языка. Т. 1. СПб.; М.: Тип. М. О. Вольфа, 1880. 812 с. [электронный реcypc] // URL: https://runivers.ru/upload/iblock/ bda/Tolkovyi\%20slovar\%20Dalya\%202.pdf (дата обращения: 22.02.2019).

Даль 1881 - Даль В. Толковый словарь живого великорусского языка. Т. 2. И - О. СПб.; М.: Тип. М. О. Вольфа, 1881. 807 с. [электронный ресурс] // URL: https://runivers.ru/ upload/iblock/bda/Tolkovyi\%20slovar\%20 Dalya\%202.pdf(дата обращения: 22.02.2019).

40 Здесь и далее при ссылках на тибетский буддийский канон приводится каталожный номер к изданию Дерге. См., напр.: Guide to the Nyingma Edition of the sDe-dge $\boldsymbol{b K a}$ ' 'gyur /bsTan 'gyur. Ed. By Tarthang Tulku. Berkeley, California: Dharma Publishing, 1980. 1148 p.

${ }^{41}$ Here and in further references to the Tibetan Buddhist Canon the paper uses respective catalogue ID numbers of the Derbe Edition. E.g., see, Guide to the Nyingma Edition of the sDe-dge $\boldsymbol{b} \boldsymbol{K} \boldsymbol{a}$ ' ' gy $\boldsymbol{u} \boldsymbol{r}$ /bsTan 'gyur. Ed. By Tarthang Tulku. Berkeley, California: Dharma Publishing, 1980. 1148 p.
С точки зрения квантово-механической интерпретации Эверетта-Менского, абсолютная реальность является лишь суперпозицией относительных, классических реальностей; о существовании некоей отдельной запредельной реальности, не подлежащей прямым или косвенным наблюдениям, в физике речь не идёт. Сущность - является.

Менский 2005 - Менский М. Б. Концепция сознания в контексте квантовой механики // Успехи физических наук. Т. 175. 2005. № 4. Апрель. С. 412-435.

Менский 2010 - Менский М. Б. Тайны сознания и параллельные реальности квантового мира // Культура и время. 2010. № 1. С. 110-123.

Менский 2011 - Менский М. Б. Параллельные реальности в квантовом мире и концепция сознания // Буддизм России. 2011. № 43. C. 44-45.

Ранджунг 2008 - Третий Кармапа Ранджунг Дордже. О различении сознания и изначального осознавания / пер. с тиб. В. Батаров. М.: Ганга, Шечен, 2008. 288 с.

Терентьев 2016 - Терентьев А. Переписка с Менским [электронный ресурс] // URL: http://www.buddhismofrussia.ru/books/458/ (дата обращения: 25.02.2019).

Цонкапа 2010 - Чже Цонкапа. Большое руководство к этапам Пути Пробуждения / пер. с тиб. А. Кугявичуса. 2-е изд. СПб.: Издание А. Терентьева, 2010. 1593 с.

Цонкапа 2015 - Чже Цонкапа. Сокращенное руководство к этапам Пути Пробуждения (Средний Ламрим) / пер. с тиб. А. Кугявичуса. М.: Фонд «Сохраним Тибет», 2015. 642 с.

Чандракирти 2004 - Чандракирти. Введение в мадхьямику (с комментариями автора). Пер. с тиб. А. Донца. СПб.: Евразия, 2004. 464 с.

Cabezón et al. 2007 — Cabezón, José Ignacio; Geshe Lobsang Dargyay. Freedom from Extremes. Gorampa's "Distinguishing the Views" and the Polemics of Emptiness. Boston: Wisdom Publications. 2007. 418 p.

Candrakīrti 1906-Candrakīrti. Mūlamadhyamakakārikās de Nāgārjuna avec la Prasannapadā Commentaire de Candrakīrti. Publiè par L. de la Vallee Poussin. Bibliotheca Buddhica, 4, St. Petersbourg: Imprimerie de l'Académie Impériale des Sciences, 1906.

Smetham 2017 - Smetham Graham. Quantum Path to Enlightenment. Researches inspired by the Quantum Buddhist Psycho-Metaphysics of Michael Mensky. Published by Lulu Press, Inc., 2017. 394 p. 
Everett 1957 - Everett, H. (III) «Relative State» Formulation of Quantum Mechanics // Review of Modern Physics. 1957. Vol. 29. N. 3. July. Pp. 454-462.

Jinpa 2002 - Jinpa, Thupten. Self, Reality and Reason in Tibetan Philosophy: Tsongkhapa's Quest for the Middle Way. London and New York: Routledge Curzon, 2002. 248 p.

Karunadasa 2014 - Karunadasa, Y. The Theravada Abhidhamma. Hong Kong: Centre of Buddhist Studies, The University of Hong Kong, 2014. $377 \mathrm{p}$.

Narain. The Nature of Madhyamaka Thought // The Madhyamaka Dialectic and the Philosophy of Nāgārjuna. (ed.) by Samdhong, Rinpoche. Sarnath. [No date].

Ruegg 1981 - Ruegg, David Seyfort. The Literature of the Madhyamaka School of Philosophy in India. Wiesbaden: Otto Harrassowitz. 1981. $146 \mathrm{p}$.

Ruegg 2002 - Ruegg, David Seyfort. Two Prolegomena to Madhyamaka Philosophy. Studies in Indian and Tibetan Madhyamaka Thought. Part 2. Wien: Arbeitskreis für Tibetische und Buddhistische Studien Universität Wien, 2002. 300 p.

Stcherbatsky 1936 - Madhyānta-vibhañga. Discourse on Discrimination between Middle and Extremes ascribed to Bodhisattva Maitreya and commented by Vasubandhu and Sthiramati / Tr. from the Sanskrit by Th. Stcherbatsky. SPb.: Bibliotheca Buddhica. 1936. Vol. 30. $170 \mathrm{p}$.

Thakchoe 2007 - Thakchoe S. The Two Truths Debate. Tsonkhapa and Gorampa on the Middle Way. Boston: Wisdom Publications. 2007. 245 p.

The Princeton Dictionary of Buddhism 2013 - The Princeton Dictionary of Buddhism. By Buswell, Robert E. Jr., Lopez, Donald S. Jr. Princeton and Oxford, 2013. 1304 p.

Thrangu 2000 - Thrangu Rinpoche. Distinguishing the Middle from the Extremes (Skt. Madhyantavibhanga) by Asanga based on the inspiration of the Buddha Maitreya. A Commentary by Thrangu Rinpoche / Tr. by Jules Levinson. Boulder: Namo Buddha Seminar. 2000. 106 p.

Tsong kha pa 1997 — Tsong kha pa drang nges legs bshad snying po (=Легко изложенная суть [различения] буквального и подлинного) // Geshe Yeshe Tabkhe's Shar Tsong kha pa'i drang ba dang nges pa'i bstan chos legs bshad snying po (= Геше Еше Табке. «Легко изложенная суть [различения] буквального и подлинного» [- произведение] Цонкапы с востока). Sarnath: CIHTS, 1997.
Zeilinger 2003 - Zeilinger, Anton. Encounters Between Buddhist and Quantum Epistemologies // Buddhism and Science. Breaking New Ground. Ed. by B. Alan Wallace. Columbia series in science and religion. New York: Columbia University, 2003. Pp. 387-398.

Zhamar 2012 - Zhamar Gedun Tenzin Gyatso. lhag mthong chen mo'i dka' 'grel dgongs zab snang ba'i sgron me // Byang chub lam gyi rim pa khrid yig. Vol. 4 (a mdo zhwa dmar dge ,dun bstan ,dzin rgya mtsho, 1852-1912: Commentaries on the Stages of the Path to Enlightenment). Manipal. 2012 (неопубликованный перевод А. Кугявичуса).

\section{References}

Cabezón, José Ignacio; Geshe Lobsang Dargyay. Freedom from Extremes. Gorampa's 'Distinguishing the Views' and the Polemics of Emptiness. Boston: Wisdom Publications, 2007. 418 p. (In Eng.)

Candrakīrti. Introduction to Madhyamaka. A. Donets (transl.). St. Petersburg: Evraziya, 2004. 464 p. (In Russ.)

Candrakīrti. Mūlamadhyamaka-kārikās de Nāgārjuna avec la Prasannapadā Commentaire de Candrakīrti. Publ. by L. de la Vallèe Poussin. Bibliotheca Buddhica, 4. St. Petersburg: Imper. Acad. of Sc., 1906. (In Sanskr. and Fr.)

Dahl V. I. Explanatory Dictionary of the Living Great Russian Language. Vol. 1. St. Petersburg; Moscow: M. O. Wolf, 1880. 812 p. An Internet resource: https://runivers.ru/upload/iblock/ bda/Tolkovyi\%20slovar\%20Dalya\%202.pdf (accessed: February 22, 2019). (In Russ.)

Dahl V. I. Explanatory Dictionary of the Living Great Russian Language. Vol. 2. Letters ' И - О'. St. Petersburg; Moscow: M. O. Wolf, 1881. 807 p. An Internet resource: https:// runivers.ru/upload/iblock/bda/Tolkovyi $\% 20$ slovar\%20Dalya\%202.pdf (accessed: February 22, 2019). (In Russ.)

Everett, H. (III) 'Relative State' Formulation of Quantum Mechanics. Review of Modern Physics. 1957. Vol. 29. No. 3. July. Pp. 454462. (In Eng.)

Smetham, Graham. Quantum Path to Enlightenment. Researches inspired by the Quantum Buddhist Psycho-Metaphysics of Michael Mensky. Lulu Press Inc., 2017. 394 p. (In Eng.)

Hegel G. W. F. The Science of Logic. Vol. II. Moscow: Mysl', 1971. 248 p. (In Russ.)

Jinpa, Thupten. Self, Reality and Reason in Tibetan Philosophy: Tsongkhapa's Quest for the Middle Way. London and New York: Routledge Curzon, 2002. 248 p. (In Eng.) 
Karunadasa, Y. The Theravada Abhidhamma. Hong Kong: Centre of Buddhist Studies, The University of Hong Kong, 2014. 377 p. (In Eng.)

Madhyānta-vibhangga. Discourse on Discrimination between Middle and Extremes Ascribed to Bodhisattva Maitreya and Commented by Vasubandhu and Sthiramati. Th. Stcherbatsky (transl.). St. Petersburg: Bibliotheca Buddhica, 1936. Vol. 30. 170 p. (In Russ.)

Mensky M. B. Conception of consciousness in the context of quantum mechanics. Uspekhi Fizicheskikh Nauk. Vol. 175. 2005. No. 4, April. Pp. 412-435. (In Russ.)

Mensky M. B. Mysteries of consciousness and parallel realities in the quantum world. Kul'tura i Vremya. 2010. No. 1. Pp. 110-123. (In Russ.)

Mensky M. B. Parallel realities in the quantum world and the concept of consciousness. Buddhism of Russia. 2011. No. 43. Pp. 44-45. (In Russ.)

Narain H. The Nature of Madhyamaka Thought. In: The Madhyamaka Dialectic and the Philosophy of Nāgārjuna. Samdhong Rinpoche (ed.). Sarnath. Pp. 175-196. (In Eng.)

Ranjung Dorje. Distinction of Consciousness and Primordial Awareness. V. Batarov (transl.). Moscow: Ganga, Shechen, 2008. 288 p. (In Russ.)

Ruegg, David Seyfort. The Literature of the Madhyamaka School of Philosophy in India. Wiesbaden: Otto Harrassowitz. 1981. 146 p. (In Eng.)

Ruegg, David Seyfort. Two Prolegomena to Madhyamaka Philosophy. Studies in Indian and Tibetan Madhyamaka Thought. Part 2. Wien: Arbeitskreis für Tibetische und Buddhistische Studien Universität Wien, 2002. 300 p. (In Eng.)
Terentyev A. [Letters between M. Mensky and A. Terentyev]. An Internet resource: http://www. buddhismofrussia.ru/books/458/ (accessed: February 25, 2019). (In Russ.)

Thakchoe S. The Two Truths Debate. Tsonkhapa and Gorampa on the Middle Way. Boston: Wisdom Publications. 2007. 245 p. (In Russ.)

The Princeton Dictionary of Buddhism. Buswell, Robert E. Jr., Lopez, Donald S. Jr. (comps.). Princeton and Oxford, 2013. 1304 p. (In Eng.)

Thrangu Rinpoche. Distinguishing the Middle from the Extremes (Skt. Madhyantavibhanga) by Asanga Based on the Inspiration of the Buddha Maitreya. A Commentary by Thrangu Rinpoche. Jules Levinson (transl.). Boulder: Namo Buddha Seminar, 2000. 106 p. (In Eng.)

Tsong kha pa drang nges legs bshad snying po. An Easily Explained Essence [for the Differentiation between] the Literal and True. In: Geshe Yeshe Tabkhe [Comments]. Sarnath: CIHTS, 1997. (In Tib.)

Tsong kha pa, The Middle Length Treatise to the Stages of the Path of Awakening (Middling Lamrim). A. Kugevičius (transl.). Moscow: Save Tibet Foundation, 2015. 642 p. (In Russ.)

Tsong kha pa. A Great Treatise on the Stages of the Path to Awakening. A. Kugevičius (transl). $2^{\text {nd }}$ ed. St. Petersburg: A. Terentyev, 2010. 1593 p. (In Russ.)

Zeilinger, Anton. Encounters Between Buddhist and Quantum Epistemologies. In: Buddhism and Science. Breaking New Ground. B. Alan Wallace (ed.). New York: Columbia University, 2003. Pp. 387-398. (Eng.)

Zhamar Gedun Tenzin Gyatso. Commentaries on the Stages of the Path to Enlightenment. In: Byang chub lam gyi rim pa khrid yig. Vol. 4. Manipal, 2012. (An unpublished translation by A. Kugevičius). (In Russ.) 